\title{
Persistent decline in abundance of harbor seals Phoca vitulina richardsi over three decades in Aialik Bay, an Alaskan tidewater glacial fjord
}

\author{
Anne Hoover-Miller ${ }^{1,2, *}$, Shannon Atkinson ${ }^{3}$, Suzanne Conlon ${ }^{1}$, Jill Prewitt ${ }^{1}$, \\ Peter Armato ${ }^{2,4}$
}

\author{
${ }^{1}$ Alaska SeaLife Center, Seward, Alaska 99664, USA \\ ${ }^{2}$ School of Fisheries and Ocean Sciences, University of Alaska Fairbanks, Fairbanks, Alaska 99775, USA \\ ${ }^{3}$ Juneau Center School of Fisheries and Ocean Sciences, University of Alaska Fairbanks, Juneau, Alaska 99801, USA \\ ${ }^{4}$ Ocean Alaska Science and Learning Center, National Park Service, Seward, Alaska 99664, USA
}

\begin{abstract}
Glacial ice calved from tidewater glaciers in Alaska provides an important haulout habitat for harbor seals Phoca vitulina richardsi, and its extent and ecological influence is being reduced by climate change. The number of harbor seals using glacial ice adjacent to Aialik Glacier, central Gulf of Alaska, declined by $93 \%$ from 1979 to 2009. During this time, seals demonstrated variability in their selection of haulout locations, particularly during the molt. Near Pedersen Glacier, $6 \mathrm{~km}$ south of Aialik Glacier, the number of seals doubled from 2005 to 2007; this was followed by an equivalent loss from 2007 to 2009. This influx, which occurred during a period of cold marine conditions, was associated with the arrival of seals from locations outside Aialik Bay, rather than from movements of seals from Aialik Glacier. Nearly all pups were born near Aialik Glacier. Pup production, which was stable from 1979 to 1983 , subsequently declined by $12.4 \% \mathrm{yr}^{-1}$ through 1994 . Although the rate of decline abated, the numbers of pups continued to decline by $4.6 \%$ annually from 1994 to 2009 . The persistent decline of harbor seals in Aialik Bay is similar to that observed in Glacier Bay, southeast Alaska, but contrasts with trends at nonglacial sites in the Gulf of Alaska and southeast Alaska where populations have been increasing since the mid-1990s. Results indicate flexibility in selection of haulout location and potentially the proportion of time seals are present on the ice. The persistent decline in pup production, however, raises concern over the future of harbor seals in previously important glacial pupping habitats and the integrity of unique glacial fjord ecosystems.
\end{abstract}

KEY WORDS: Harbor seal · Phoca vitulina richardsi · Glaciers · Population decline · Gulf of Alaska Resale or republication not permitted without written consent of the publisher

\section{INTRODUCTION}

Harbor seals Phoca vitulina in the North Pacific Ocean inhabit diverse coastal environments extending from Mexico to Japan, and northward into the Bering Sea. Haulout habitats include rocks, beaches, tidal flats, sea ice, glacial ice and anthropogenic structures (Hoover-Miller 1994). In Alaska, approximately $10 \%$ of the harbor seals $P$. $v$. richardsi haul out on glacial ice calved from tidewater glaciers that terminate in marine and lake environments (Bengtson et al. 2007).
The number of harbor seals at haulouts in central and western regions of the Gulf of Alaska declined precipitously from the time when counts were made during the mid-1970s to mid-1980s (Pitcher 1990, Frost et al. 1999, Small et al. 2003, 2008). In the Aleutian Islands, Small et al. (2008) estimated a $67 \%$ decline from 1977 to 1999, with the greatest loss occurring in the western Aleutian Islands. Seals at Tugidak Island, $55 \mathrm{~km}$ southwest of Kodiak Island, experienced a $21 \% \mathrm{yr}^{-1}$ decline from 1976 to 1978 that moderated to $7 \% \mathrm{yr}^{-1}$ through 1988 (Pitcher 1990) and stabilized in 
the late 1980s to mid-1990s. Since 1994 harbor seals near Kodiak Island have been increasing at about 6 to $7 \%$ annually (Jemison \& Kelly 2001, Small et al. 2003, Jemison et al. 2006). In central Prince William Sound, the number of seals counted from 1984 to 1988 declined by about $40 \%$ (Frost et al. 1994); from 1990 to 1997, the rate of decline diminished to $4.6 \% \mathrm{yr}^{-1}$ contributing to an overall population reduction of $63 \%$ from 1984 to 1997 (Frost et al. 1999) followed by a stabilization and slow recovery (G. Pendleton, Alaska Department of Fish and Game, unpubl. data.). These declines coincided with ecological changes observed after the 1976 to 1977 shift in the Pacific Decadal Oscillation (Pitcher 1990, Hare \& Mantua 2000, Jemison \& Kelly 2001), but proximate causes for the declines have not been determined, nor has it been determined when the declines began.

Harbor seal haulout attendance varies throughout the year and is sensitive to multiple environmental factors that can differ on a site-specific basis (e.g. Ver Hoef \& Frost 2003). Harbor seals typically exhibit a bimodal seasonal haulout pattern where highest numbers are observed when seals are pupping and during their molt (Frost et al. 1999, Jemison \& Kelly 2001, VerHoef \& Frost 2003, Jemison et al. 2006). In Alaska, long-term population monitoring has concentrated on counts conducted during the molt; relatively few locations have been studied during pupping (Hoover 1983, Frost et al. 1994, Jemison \& Kelly 2001, Jemison et al. 2006, Mathews \& Pendleton 2006, Womble et al. 2010). At terrestrial haulouts in Alaska, common environmental covariates of haulout include date, tide, time of day, disturbance and weather (Hoover-Miller 1994, Frost et al. 1999, Boveng et al. 2003, Small et al. 2003, Ver Hoef \& Frost 2003, Jemison et al. 2006). At glacial ice habitats, environmental covariates include similar factors albeit with differing tidal effects (Hoover 1983, Calambokidis et al. 1987, Mathews \& Pendleton 2006, Bengtson et al. 2007).

Tidewater glacial habitats are unique environments that differ markedly between locations with respect to glacial activity and fjord morphology (Molnia 2008). Ice availability is influenced by fjord and glacier morphology, calving rates, current and past weather, water temperatures and season. Ice tends to be most abundant in spring (May to June) and diminishes in abundance as the summer progresses (Hoover 1983). Unlike terrestrial habitats, ice substrates are not flooded by tides and ice provides multiple haulout access points, allowing seals to aggregate in groups to benefit from group vigilance while reducing substrate-forced contact and crowding (Hoover 1983).

Several studies have investigated harbor seals that depend on glacial ice for haulout (Bishop 1967, Hoover 1983, Calambokidis et al. 1987, Mathews \& Kelly 1996,
Hoover-Miller et al. 2001, Savarese 2004, Mathews \& Pendleton 2006, Bengtson et al. 2007, Womble et al. 2010). With the exception of research conducted in Glacier Bay since 1972 (Calambokidis et al. 1987, Mathews \& Pendleton 2006, Womble et al. 2010), longterm assessments of haulout behavior and population trends are lacking for ice-associated harbor seals in Alaska.

The primary objective of the present study was to estimate population trends of seals in Aialik Bay during the past $30 \mathrm{yr}$, based on pup counts and counts of seals present during the molt. To improve sensitivity and reduce variation resulting from factors unrelated to real changes in the numbers of seals, we used covariates to incorporate influences of environmental and observer-related factors that influence haulout and detection of seals (Adkison et al. 2003, Small et al. 2003, Mathews \& Pendleton 2006).

\section{MATERIALS AND METHODS}

Study sites. Aialik Bay, located $23 \mathrm{~km}$ southwest of the town of Seward, Alaska, is a $31 \mathrm{~km}$ long, $270 \mathrm{~m}$ deep fjord located within the Kenai Fjords National Park (Fig. 1). It is flanked by steep mountains and convoluted shorelines with a prominent $10 \mathrm{~m}$ deep sill (underwater moraine) extending eastward from Pedersen Lagoon, $8 \mathrm{~km}$ southeast of Aialik Glacier's current terminus. Three tidewater glaciers (Aialik, Pedersen and Holgate) are located in Aialik Bay, but only ice calved from Aialik and Pedersen glaciers is regularly used by harbor seals for haulout. Terrestrial haulouts are uncommonly used in Aialik Bay.

Aialik Glacier: Aialik Glacier flows from the northwest shoreline at the head of Aialik Bay, terminating directly into the bay. Although the terminus fluctuates seasonally and between years, it has remained relatively stable during the past century (Grant \& Higgins 1913, Post 1980, Molnia 2008). Ice calved from Aialik Glacier circulates around Squab Island $(2 \mathrm{~km}$ east of the face of the glacier) and generally remains north of the sill.

Pedersen Glacier: A mountain ridge (approximately 300 to $1200 \mathrm{~m}$ high) partially surrounds the Pedersen glacial basin, separating Pedersen and Aialik glaciers. Pedersen Glacier is a receding glacier that terminated on the Aialik Bay shoreline in the late 1800s (Grant \& Higgins 1913). The Pedersen Lake study site, $6 \mathrm{~km}$ south of Aialik Glacier (12 km by water), was completely covered by Pedersen Glacier in 1960. Although tidally influenced, Pedersen Lake directly exchanges water with Pedersen Lagoon via a shallow stream. Pedersen Lagoon directly exchanges water with Aialik Bay through a larger stream channel. Most ice suitable 


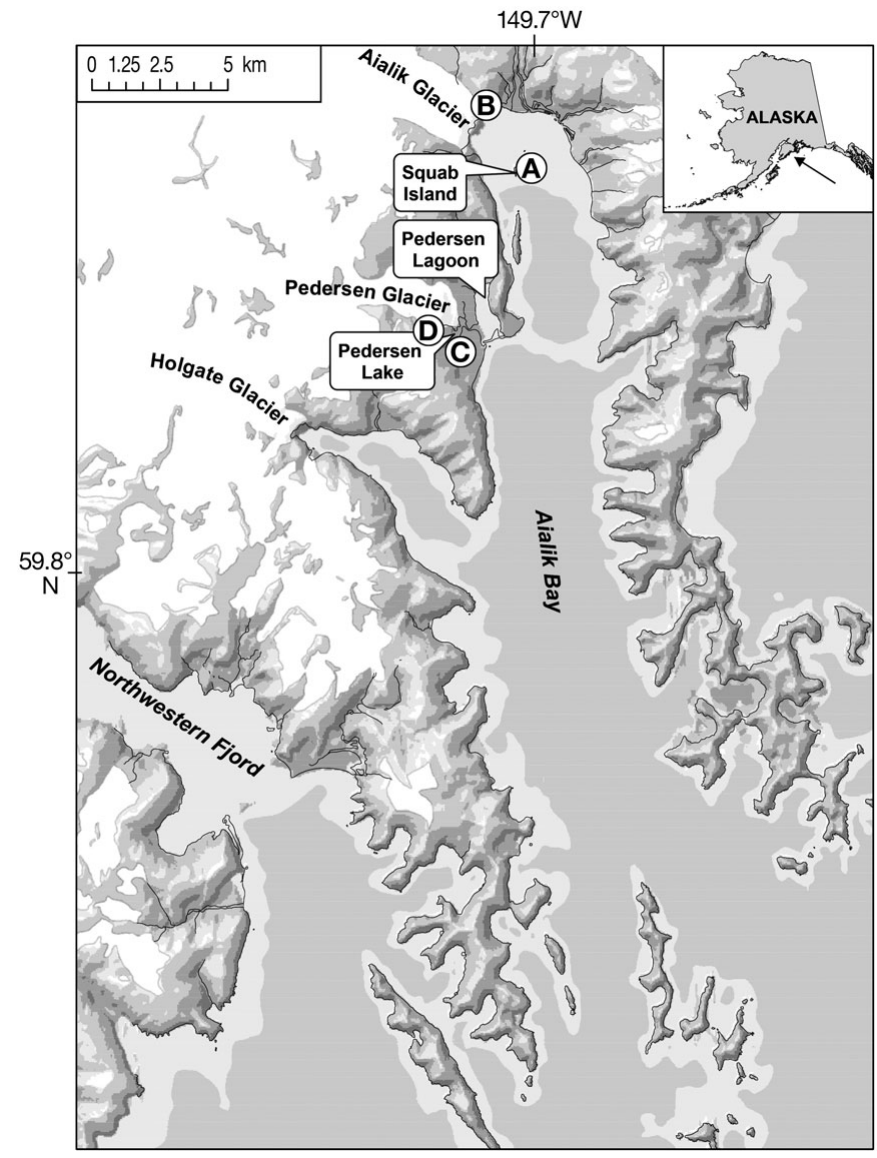

Fig. 1. Location of Aialik Bay, Alaska, showing the location of the Aialik and Pedersen glacial ice habitats. Letters designate locations of the following remote video camera sites: A: Squab Island; B: Aialik Glacier; C: Pedersen Lake; D: Pedersen Glacier

for harbor seal haulout is retained in Pedersen Lake by surrounding moraines. From 1979 to 1981 Pedersen Lake was relatively small and use by seals was not evident to researchers or local bush pilots who frequently flew over the lake. Seals were first noted using the lake in 1992 (J. Pfeiffenberger, National Park Service, unpubl. data.).

Field studies: 1979 to 1997 . Field studies were conducted by A.H.M. in upper Aialik Bay from 17 May to 17 August 1979 and 15 May to 23 August 1980. Surveys of marine mammals were conducted at the head of Aialik Bay from the northern end of Squab Island by observers who used $7 \times 35$ binoculars and a 15 to $45 \times$ spotting scope. For each survey the date, time, tide, weather (percent cloud cover, wind direction, wind velocity, precipitation), ice density and direction of ice movement were recorded. During each survey, the water and ice between Squab Island and the shore was scanned methodically and the total number of all seals observed on the ice and in the water were recorded. In all, 125 surveys were conducted in 1979 and 130 in 1980. Owing to poor visibility, counts were not always conducted during periods of fog, heavy rain and/or wind speeds exceeding $10 \mathrm{~m} \mathrm{~s}^{-1}$ (20 knots).

From 1983 through 1997, 193 surveys were conducted from Squab Island by A.H.M. and trained observers from the National Park Service who used methods similar to the 1979 to 1981 surveys. Repetitive counts were conducted during favorable haulout conditions when seals were pupping ( 3 to 26 June, $n=63$ ) and during the molt (25 July to 18 August, $\mathrm{n}=130$ ). During the $1990 \mathrm{~s}$, counts were conducted by 2 observers concurrently and then averaged.

Remote video monitoring: 2002 to 2009. Remotely controlled video monitoring equipment developed and maintained by SeeMore Wildlife and operated at the Alaska SeaLife Center (ASLC) in Seward, Alaska, was installed in June 2002 to observe harbor seals in Aialik Bay. The equipment included visible light, block video cameras with $25 \times$ optical and up to $300 \times$ digital zoom. The cameras were mounted in weatherproof housings that included a remote controlled pan, tilt, zoom, and windshield wiper and washer assemblies. Cameras were controlled via computers located at the ASLC. User-selected control signals were transmitted, via a series of 3 to 4 repeaters, more than $90 \mathrm{~km}$ to the desired camera via UHF. Video signals were transmitted along the reciprocal path to the ASLC via a series of microwave repeaters. Observers immediately recorded data from live images. Time-lapse recordings were concurrently taken to provide a record of environmental conditions, seal distribution, interactions between humans and seals, and when viewing opportunities were suitable, the behavior of seals. Cameras initially were installed on Squab Island (Site A, Fig. 1) at the head of Aialik Bay and on the south side of Pedersen Lake near Pedersen Glacier (Site C, Fig. 1) in 2002. In 2003, the system expanded to include a camera site on the north side of Aialik Glacier (Site B, Fig. 1) to observe the glacier-face environment, and in 2005 a site was installed on the south side of Pedersen Glacier (Site D, Fig. 1) to accommodate the expanding lake habitat that was exposed as Pedersen Glacier retreated.

Video camera surveys were initiated with cameras on Squab Island. An ice scan that used predefined positions captured a panorama of images covering a $360^{\circ}$ view to show the ice distribution and overall survey conditions (cloud cover, precipitation and sea state). Ice and water from Squab Island to shore was methodically scanned by following parallel tracks to shore at different magnifications. Observations of seals present on the ice were immediately recorded on data forms. Swimming seals were distinguished from seals 
on the ice but were not included in the count owing to differences in probabilities of being sighted and to reduce potential for counting seals twice. Weather conditions including percent cloud cover, wind direction, wind velocity (assessed using a modified Beaufort scale that reflected the reduced fetch of the upper bay together with an RM Young model 05106 anemometer, installed on Squab Island in 2004), precipitation and composite weather $(1=$ full sun, $2=$ partial clouds to overcast, 3 = precipitation and wind $>20$ knots) were recorded.

During pupping (days of year 145 to $177 ; 24$ May to 26 June) and molting (days of year 206 to 238; 25 July to 25 August), counts were tabulated for both Aialik and Pedersen glaciers. Total Counts refer to the total number of seals counted near Aialik and Pedersen glaciers during sequential surveys. Surveys during 2002 were conducted during midday (11:30 to 13:30 h) and at other times as opportunity allowed. In 2003 to 2004, surveys were conducted at approximately 09:00, $11: 30,13: 00,15: 00$ and 17:00 h. To broaden diurnal coverage during focal periods for pupping (4 to 7 June and 11 to 14 June) and molting (1 to 8 August), in 2004 to 2007, additional surveys were conducted at 07:00, 08:00, 10:00 and 19:00 h. In 2008 and 2009, the surveys were only conducted at 09:00, 11:00, 13:00, 15:00 and 17:00 h. Seals were distinguished as mother-pup pairs, seals without pups and all seals including pups (total seals). The numbers of pups indicate productivity of seals resident in Aialik Bay. Nearly all pups are born on ice near Aialik Glacier. Counts of mother-pup pairs included the few pups born in Pedersen Lake and those temporarily using Pedersen Lake for haulout. For this study, young pups without their mothers were excluded from analysis as they were uncommonly observed and if abandoned at a young age had virtually no chance of survival (Hoover 1983). Backlighting interfered with distinguishing pelage characteristics of seals viewed by means of the video camera system. Although backlighting did not obstruct the detection of seals, it did impede distinguishing weaned pups from yearlings. Similarly, unless viewed under ideal conditions, older pups without their mother could not be distinguished from weaned pups or small yearlings; thus, older lone pups and weaned pups were included with seals without pups.

Covariates. Date was partitioned into Year and Day of Year to distinguish interannual and seasonal effects. Seasonal periods analyzed included pupping and molting. All analyses were based on Day of Year; calendar dates shown in this paper are presented for reference but do not reflect leap year.

Tidal data used for analysis were based on the actual height of the water measured hourly at the Seward tide station (no. 9455090). NOAA tide predictions are iden- tical between Seward and north Aialik Bay with respect to time and height of high tides. Low tides in Seward occur 12 min later than in north Aialik Bay and are $2 \%$ greater in height. Seward was used as the reference site because of the availability of actual tidal measurements. We calculated Tide Velocity $\left(\mathrm{m} \mathrm{min}^{-1}\right)$ as the difference in tide height $(\mathrm{m})$ at the onset of the survey hour and the subsequent hour, divided by $60 \mathrm{~min}$. Negative values correspond to falling tides while positive values correspond to rising tides. Tide Height was estimated as the mean tide height on the hour before the start of the survey and the subsequent hour.

Sunrise, sunset and Lunar (the percent of moon's visible disk illuminated), were obtained from the US Naval Observatory, Astronomical Applications Department. Solar noon was calculated as the midpoint between sunrise and sunset and was adjusted for Daylight Savings Time and the 1983 change in Alaska Time Zones. Time from solar noon (Time) was calculated as the difference between the time at the beginning of the survey and solar noon on that date, with negative numbers indicating morning hours and positive numbers representing afternoon and evening hours.

Before each survey, percent cloud cover, wind direction, wind velocity and precipitation were recorded. Weather parameters (Weather) were grouped into the following categories: sun/overcast (periods without strong winds or precipitation), rain/fog (periods of light to moderate rain and/or fog), heavy rain/fog (periods of extensive rain or fog that impeded counts owing to poor visibility in addition to effects on the seal behavior) and winds exceeding $10 \mathrm{~m} \mathrm{~s}^{-1}$ (20 knots). Strong northwesterly winds generated different effects near Aialik and Pedersen glaciers. Northwest winds rapidly dispersed ice near Aialik Glacier, thereby restricting the availability of haulout substrate. At Pedersen Lake, however, surrounding mountains often sheltered the lake from northwest winds. Even during windy weather, ice was retained in Pedersen Lake owing to shallow glacial moraines and stream drainage.

The quality of surveys was affected by camera responsiveness and visibility, distribution of seals and ice, and distractions in the field (e.g. presence of vessels near ice) or at the monitoring station. Survey quality at Aialik Glacier (Quality Aialik$_{\text {) }}$ and Pedersen Glacier (Qualitypedersen) represent summarized qualitative assessments based on observer survey quality designations and comments. Count quality assignments consisted of $1=$ excellent to good, $2=$ fair and $3=$ poor.

Statistical analysis. Analytical methods of effects of environmental covariates on haulout generally followed those of Small et al. (2003) and Mathews \& Pendleton (2006). Counts of seals on ice near Aialik and 
Pedersen glaciers and Total Counts based on successive counts of both locations were treated separately.

Covariate analysis: Environmental covariates of haulout during molting were evaluated using generalized linear models (GLM) with error based on a quasiPoisson distribution and log link (Link \& Sauer 1997, Small et al. 2003, Mathews \& Pendleton 2006). Model evaluation and selection were conducted with $\mathrm{R}$ v. 2.11.0 statistical programming language (R Development Core Team 2010) with the glmulti v. 06.-3 (Calcagno 2009) and AICcmodavg (Mazerolle 2009) packages for R. Visualization of predicted responses and optimization of parameters were facilitated with the JMP (v. 8.02) factor profiler (SAS Institute 2009). The JMP factor profiler calculates predicted estimates based on settings of each factor in the model. Sensitivity, the partial derivative of the factor's profile function at a selected value, was used to determine the apex of a factor's contour curve. Optimization was achieved by setting each factor to the value that maximized prediction estimates while minimizing the confidence intervals of the resulting estimates and sensitivity of each factor included in the model.

For each analysis, we fit GLMs with log-link and quasi-Poisson distribution to identify influential covariates and estimate trends. The importance index, ranging from 0 (unimportant) to 1 (very important) was calculated for each covariate. Error associated with estimates was determined by refitting covariates with importance estimates of $>0.85$ by means of quasiPoisson distribution and log-link. Covariates with importance indices $<0.85$ were not included because of their minimal influence on estimated trends (Mathews \& Pendleton 2006). Initial models included the following variables: Year, Day of Year, Time, Tide Height, Lunar, Weather and Quality Aialik or QualityPedersen. Interactive terms were included for Day of Year $\times$ Year to allow Day of Year response to vary by year. For comparisons involving the full data set, from 1979 to 2009, Year was treated categorically to allow interannual changes to vary independently from overall trend. Models based on years 2002 to 2009 used Year as a continuous variable for modeling current trends. To allow for nonlinear responses, quadratic terms were included for Day of Year and Time. Quadratic effects were not included for Lunar (29.5 d cycle) as our interest was in potential effects of nocturnal light (Trillmich \& Mohren 1981, Watts 1993) rather than amplitude of tides that would be correlated with Tide Height (12 h, $25 \mathrm{~m}$ cycle). Both Tide Height and Tide Velocity were considered for inclusion in models but owing to their highly correlated behavior, only one was used in our models. To determine the variable with the strongest potential for contribution to final models, we included each variable in preliminary screening models and retained Tide Height in subsequent analyses owing to its greater effect.

Trend estimates and SEs were obtained as a weighted average of estimates from the individual models with weights based on corrected Akaike's Information Criteria (AICc). The model-averaging procedure incorporates uncertainty about which model was most appropriate for determining trend estimates and variance, though in nearly every case, the average and fully weighted best model were equivalent.

Standardization and determination of population trends: Estimates of trend trajectories were based on GLM averaged models (Means) and standardized estimates based on favorable haulout conditions (Adjusted). Adjusted estimates and associated 95\% CIs were obtained from predicted values generated by least-squares fits after setting factors to specific values representing favorable haulout conditions. We defined population trend as the geometric mean rate of change over the interval of interest (Small et al. 2003). Owing to the prolonged duration of this study, we evaluated assumptions that the haulout behavior of seals at Aialik Glacier was similar over the $30 \mathrm{yr}$ time span and that application of the same models to field and camera counts altered estimates. Initially field (1979 to 1998) and camera (2002 to 2009) data sets were screened separately to assess whether haulout behavior changed over time or differences in methods confounded models. Because resulting models and estimates were nearly identical, we applied models based on all counts, camera and field.

The timing of pupping can vary between years (Jemison \& Kelly 2001, Jemison et al. 2006). Although counts were based on favorable haulout conditions, Day of Year was further adjusted each year to accommodate changes in pupping phenology. During the molt, Day of Year was standardized across years since the age and sex composition of molting seals changes seasonally (Daniel et al. 2003). Thus, for trend analysis based on molt counts, model-averaged trends were determined for specified dates.

\section{RESULTS}

\section{Haulout covariates}

\section{Pupping}

During pupping, haulout covariates were evaluated for mother-pup pairs and seals without pups from 1979 to 2009. Total counts of mother-pup pairs and seals without pups varied with Year, Day of Year, Time, Tide Height, Lunar, Weather, Quality Aialik $_{\text {and }}$ 


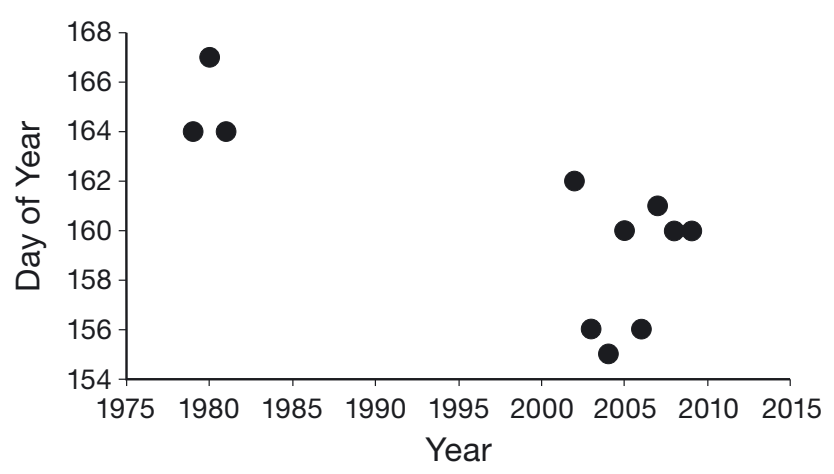

Fig. 2. Phoca vitulina richardsi. Interannual variation in Day of Year associated with peak numbers of mother-pup pairs from 1979 to 2009 in Aialik Bay, Alaska

interactive effects of Year $\times$ Day of Year. Highest counts were associated with good quality surveys taken near solar noon during calm, sunny/overcast conditions, at higher tidal stages and during a new moon. Interactive effects between Year and Day of Year reflected interannual changes in peak haulout dates between years, with earlier dates representing peak pup counts in recent years (Fig. 2). Influences of covariates on 2002 to 2009 model estimates and modeled trends based on a standardized set of covariates representing favorable conditions are compared in Table 1. For this comparison, Day of Year was fixed at 159 (June 8). Numbers of mother-pup pairs tended to be less affected by environmental factors than were other seals (Table 1). Removal of Day of Year or Time from the model had strong effects on estimated means and associated trend estimates; removal of Weather or Tide Height from the model diminished estimated means but not trend. The full model increased the estimated means resulting in a $15 \%$ reduced rate of decline over estimates calculated without covariates. Trend estimates for seals without pups were most affected by Time but were also influenced by Day of Year, Weather and Tide Height.

\section{Molt}

The relative importance of covariates in GLM models of counts conducted from 2002 to 2009 during the molt is compared for seals counted near Aialik and Pedersen glaciers and for Total Counts (Table 1). During the molt, covariates associated with haulout differed between Aialik and Pedersen glaciers. Near Aialik Glacier, the numbers of seals varied with Year, Day of Year, Time, Tide Height, Lunar, Weather, Quality Aialik and interactive effects of Year $\times$ Day of Year. The highest numbers of seals were counted near solar noon, during periods of calm, sunny or overcast weather with peak numbers of seals varying in Day of Year between years. Lowest counts were associated with periods of heavy rain and fog and, particularly near Aialik Glacier, when strong northwest winds decreased ice availability. Effects of Lunar were apparent at Aialik and Pedersen glaciers with increased numbers associated with the full moon near Aialik Glacier and the new moon near Pedersen Glacier. Inclusion of covariates reduced trend estimates of seals near Aialik Glacier by $27 \%$ where Weather had the most influence. Counts at Pedersen Glacier increased from 2002 to 2007, then declined from 2007 to 2009. We compared effects of covariates on trends during periods of increasing and decreasing trajectories. From 2002 to 2007, inclusion of covariates nearly doubled count estimates and reduced trend estimates by $4.1 \%$. Effects of Day of Year and Tide Height were most influential on count or trend estimates. Without inclusion of covariate effects, count estimates from 2007 to 2009 were $45 \%$ lower while trend estimates were $17 \%$ less than estimates modeled with covariates. Day of Year and Tide Height tended to have stronger influences on count estimates than did other covariates. Comparisons of counts at Aialik and Pedersen glaciers and total numbers counted from 2002 to 2009 indicated weak consistency in diurnal haulout patterns near Pedersen Glacier and weak Lunar effects for overall total counts.

The age composition of actively molting seals changes throughout late summer and early fall (Thompson \& Rothery 1987, Daniel et al. 2003). Trends in total counts from 2002 to 2009 modeled for 3 phases of the molt based on age composition of seals identified by Daniel et al. (2003) is illustrated in Fig. 3. Day of Year 206 (25 July) was used to estimate trends of juvenile seals; Day of Year 220 (8 August) was used to estimate trends of subadults and adult females; and Day of Year 237 (25 August) was used to represent attendance of adult seals. Numbers of presumed juveniles increased from 2004 to 2006, after which they declined. Numbers of presumed subadults and adult females continued to increase from 2004 to 2007, but also declined in 2008 and 2009. Numbers of predominantly adult seals remained at low levels through 2006; however, in 2007 numbers abruptly increased and remained elevated through 2009.

\section{Population trends}

\section{Pupping}

Maximum counts and GLM estimates adjusted for favorable conditions taken from 24 May to 26 June for the years 1979-2009 are summarized in Table 2. Dur- 
Table 1. Phoca vitulina richardsi. Influences of covariates on counts and trend estimates of mother-pup pairs and seals without pups counted near Aialik and Pedersen glaciers during pupping and molting seasons. Trend refers to linear trend between estimate years after the removal of specified covariates. Estimate: mean count adjusted for covariates for designated year. Change refers to percent difference in the estimate or trend from the complete model and the model without the specified covariates. Time: time from solar noon; Weather: weather category; Tide Height: tide height $(\mathrm{m})$; Lunar: \% lunar illumination; Quality Aialik: survey quality (Aialik Glacier); Qualitypedersen: survey quality (Pedersen Glacier)

\begin{tabular}{|c|c|c|c|c|c|c|}
\hline & Estimate & Estimate & $\begin{array}{c}\text { Change }(\%) \\
\text { estimate }\end{array}$ & $\begin{array}{c}\text { Trend (\%) } \\
\text { annual }\end{array}$ & $\begin{array}{c}\text { Change }(\%) \\
\text { trend }\end{array}$ & Settings \\
\hline \multicolumn{7}{|l|}{ (A) Pupping } \\
\hline Aialik and Pedersen glaciers combined & 2002 & 2009 & & & & \\
\hline \multicolumn{7}{|l|}{ Mother-pup pairs } \\
\hline Complete model & 33 & 22 & 0.0 & -4.8 & 0 & \\
\hline Without covariates & 14 & 10 & -70.5 & -4.1 & 14.6 & \\
\hline Day of Year and (Day of Year) ${ }^{2}$ & 22 & 16 & -38.6 & -3.9 & 18.8 & 159 \\
\hline Time and Time ${ }^{2}$ & 27 & 19 & -20.5 & -4.2 & 12.5 & -1 \\
\hline Weather & 27 & 18 & -22.7 & -4.8 & 0 & Sun/overcast \\
\hline Tide Height & 27 & 18 & -22.7 & -4.8 & 0 & 2.88 \\
\hline Lunar & 32 & 21 & -4.5 & -4.9 & -2.1 & 0 \\
\hline Quality $_{\text {Aialik }}$ & 32 & 22 & -2.3 & -4.5 & 6.3 & 1 \\
\hline \multicolumn{7}{|l|}{ Seals without pups } \\
\hline Complete model & 82 & 252 & 0.0 & 29.6 & 0 & \\
\hline Without covariates & 43 & 133 & -47.3 & 29.9 & 1.0 & \\
\hline Day of Year and (Day of Year) ${ }^{2}$ & 73 & 215 & -13.8 & 27.8 & -6.1 & 159 \\
\hline Time and Time ${ }^{2}$ & 67 & 223 & -13.2 & 33.3 & 12.5 & -0.6 \\
\hline Weather & 64 & 202 & -20.4 & 30.8 & 4.1 & Sun/overcast \\
\hline Tide Height & 70 & 207 & -17.1 & 28.0 & -5.4 & 2.88 \\
\hline Lunar & 82 & 252 & 0.0 & 29.6 & 0 & 0 \\
\hline Quality $_{\text {Aialik }}$ & 81 & 250 & -0.9 & 29.8 & 0.7 & 1 \\
\hline \multicolumn{7}{|l|}{ (B) Molt } \\
\hline Aialik & 2002 & 2009 & & & & \\
\hline Complete model & 127 & 103 & 0.0 & -2.6 & 0.0 & \\
\hline Without covariates & 70 & 53 & -46.5 & -3.3 & -26.9 & \\
\hline Day of Year and (Day of Year) ${ }^{2}$ & 126 & 103 & -0.4 & -2.5 & 3.8 & 216 \\
\hline Time and Time ${ }^{2}$ & 120 & 95 & -6.5 & -2.9 & -11.5 & -0.77 \\
\hline Weather & 110 & 82 & -16.5 & -3.6 & -38.5 & Sun/overcast \\
\hline Tide Height & 110 & 89 & -13.5 & -2.6 & 0.0 & -1.0 \\
\hline Lunar & 117 & 99 & -6.1 & -2.1 & 19.2 & 1 \\
\hline Quality $_{\text {Aialik }}$ & 125 & 102 & -1.3 & -2.5 & 3.8 & 1 \\
\hline Pedersen & 2002 & 2007 & & & & \\
\hline Complete model & 22 & 419 & 0.0 & 360.9 & 0 & \\
\hline Without covariates & 13 & 238 & -43.1 & 346.2 & -4.1 & \\
\hline Day of Year and (Day of Year) ${ }^{2}$ & 18 & 360 & -14.3 & 382.2 & 5.9 & 224 \\
\hline Time and Time ${ }^{2}$ & 21 & 394 & -5.9 & 355.2 & -1.6 & -0.796 \\
\hline Weather & 21 & 391 & -6.6 & 352.4 & -2.4 & Sun/overcast \\
\hline Tide Height & 19 & 346 & -17.2 & 344.2 & -4.6 & -1 \\
\hline Lunar & 21 & 397 & -5.2 & 358.1 & -0.8 & 0 \\
\hline QualityPedersen & 23 & 421 & 0.7 & 346.1 & -4.1 & 1 \\
\hline Pedersen & 2007 & 2009 & & & & \\
\hline Complete model & 419 & 273 & 0.0 & -7.0 & 0 & \\
\hline Without covariates & 238 & 141 & -45.2 & -8.2 & -17.1 & \\
\hline Day of Year and (Day of Year) ${ }^{2}$ & 360 & 213 & -17.2 & -8.2 & -17.1 & 224 \\
\hline Time and Time ${ }^{2}$ & 394 & 248 & -7.2 & -7.4 & -5.7 & -0.796 \\
\hline Weather & 391 & 242 & -8.5 & -7.6 & -8.6 & Sun/overcast \\
\hline Tide Height & 346 & 211 & -19.5 & -7.8 & -11.4 & -1 \\
\hline Lunar & 397 & 241 & -7.8 & -7.9 & -12.9 & 0 \\
\hline QualityPedersen & 421 & 261 & -1.4 & -7.6 & -8.6 & 1 \\
\hline
\end{tabular}



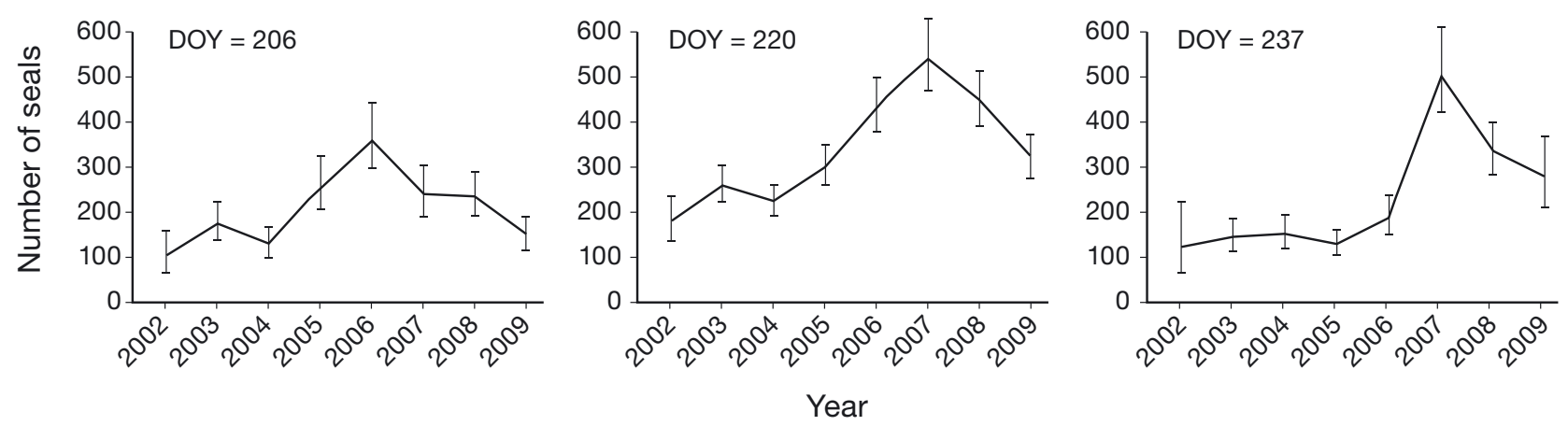

Fig. 3. Phoca vitulina richardsi. Variation in haulout during the molt during 3 differing sampling profiles. Left represents Day of Year (DOY) 206 (25 July), middle is Day of Year 220 (8 August), and right is Day of Year 237 (25 August). Vertical bars indicate $\pm 95 \%$ CI

Table 2. Phoca vitulina richardsi. Peak pupping date (Day of Year), maximum pup count, adjusted pup count estimates (based on favorable, standardized, haulout conditions and interannual differences in peak pupping date) of harbor seal pups in upper Aialik Bay from 1979-2009. Numbers in parentheses represent $95 \%$ CI. Ratios of mother-pup pairs to seals without pups (pup ratio) are based on ratios of individual surveys \pm SD. Superscripts identify the annual percent rate of change for specified time periods indicated in footnotes (negative percent indicates decline)

\begin{tabular}{|c|c|c|c|c|}
\hline Year & $\begin{array}{c}\text { Peak } \\
\text { pupping } \\
\text { (Day of Year) }\end{array}$ & $\begin{array}{l}\text { Maximum } \\
\text { count }\end{array}$ & $\begin{array}{l}\text { Adjusted } \\
\text { count }\end{array}$ & Pup ratio \\
\hline 1979 & 164 & 256 & $\begin{array}{c}212^{\mathrm{a}, \mathrm{d}} \\
(181-249)\end{array}$ & $0.27 \pm 0.25$ \\
\hline 1980 & 167 & 358 & $\begin{array}{c}289^{\mathrm{a}, \mathrm{d}} \\
(254-330)\end{array}$ & $0.34 \pm 0.20$ \\
\hline 1981 & 164 & 235 & $\begin{array}{c}259^{\mathrm{a}, \mathrm{d}} \\
(187-360)\end{array}$ & $0.30 \pm 0.19$ \\
\hline 1983 & 166 & 189 & $\begin{array}{c}265^{\mathrm{a}, \mathrm{d}} \\
(189-373)\end{array}$ & $0.46(n=1)$ \\
\hline 1989 & 166 & 92 & $\begin{array}{c}85^{\mathrm{b}, \mathrm{d}} \\
(68-106)\end{array}$ & $0.56 \pm 0.40$ \\
\hline 1994 & 166 & 40 & $\begin{array}{c}38^{\mathrm{c}, \mathrm{d}} \\
(29-50)\end{array}$ & $0.37 \pm 0.18$ \\
\hline 1995 & 166 & 28 & $\begin{array}{c}26^{\mathrm{c}, \mathrm{d}} \\
(20-35)\end{array}$ & $0.16 \pm 0.07$ \\
\hline 2002 & 162 & 38 & $\begin{array}{c}32^{\mathrm{c}, \mathrm{d}} \\
(23-44)\end{array}$ & $0.30 \pm 0.33$ \\
\hline 2003 & 156 & 45 & $\begin{array}{c}20^{\mathrm{c}, \mathrm{d}} \\
(16-26)\end{array}$ & $0.21 \pm 0.24$ \\
\hline 2004 & 155 & 59 & $\begin{array}{c}30^{\mathrm{c}, \mathrm{d}} \\
(26-36)\end{array}$ & $0.25 \pm 0.20$ \\
\hline 2005 & 160 & 53 & $\begin{array}{c}16^{\mathrm{c}, \mathrm{d}} \\
(13-20)\end{array}$ & $0.32 \pm 0.37$ \\
\hline 2006 & 156 & 50 & $\begin{array}{c}21^{\mathrm{c}, \mathrm{d}} \\
(17-25)\end{array}$ & $0.31 \pm 0.48$ \\
\hline 2007 & 161 & 48 & $\begin{array}{c}25^{\mathrm{c}, \mathrm{d}} \\
(22-30)\end{array}$ & $0.14 \pm 0.18$ \\
\hline 2008 & 160 & 44 & $\begin{array}{c}28^{\mathrm{c}, \mathrm{d}} \\
(24-33)\end{array}$ & $0.09 \pm 0.06$ \\
\hline 2009 & 160 & 32 & $\begin{array}{c}19^{\mathrm{c}, \mathrm{d}} \\
(16-23)\end{array}$ & $0.10 \pm 0.09$ \\
\hline \multicolumn{5}{|c|}{$\begin{array}{l}\text { Geometric mean of annual rate of change: } \\
\text { a } 5.8 \%(1979-1983), b_{-}-12.4 \%(1983-1994), \\
\text { c-4.6 (1994-2009), d-6.2\% }(1979-2009)\end{array}$} \\
\hline
\end{tabular}

ing that period, adjusted counts declined an average $12.4 \% \mathrm{yr}^{-1}$ from 1983 to 1994 , which reduced adjusted means from 265 to 85 pups. Numbers continued to decline by $4.6 \% \mathrm{yr}^{-1}$ through 2009 . The number of seals without pups followed similar trajectories to those of mother-pup pairs until 2007, when numbers disproportionately increased.

Pup to nonpup ratios have been used to represent productivity but also can reflect haulout of nonreproductive seals. We calculated a pup ratio based on the number of mother-pup pairs to seals without pups to contrast interannual changes in the proportion of reproducing females relative to seals without pups. Changes in the average pup ratio determined for each survey is summarized in Table 2. Pup ratios ranged from 0.21 to 0.34 until 2007 to 2009 when the pup ratio abruptly diminished to 0.09 to 0.14 . Rather than measuring productivity, however, the low pup ratios reflected an unusual abundance of seals without pups that were present during pupping.

\section{Molt}

The number of seals counted during the molt (25 July to 25 August) are summarized in Table 3 and Fig. 4. GLM estimates of the number of seals near Aialik Glacier diminished by $6.5 \% \mathrm{yr}^{-1}$ from 1979 to 1994 and $6.0 \% \mathrm{yr}^{-1}$ from 1995 to 2002. From 2003 to 2009 , the number of seals decreased by $4.1 \% \mathrm{yr}^{-1}$ (Table 3). Interpretation of Total Counts is confounded by the absence of information from Pedersen Lake until 2002 and a temporary influx of seals into Pedersen Lake from 2006 to 2008. Overall, from 2003 to 2009 , we estimated $3.9 \%$ decrease in numbers, with high variability between years. Pedersen Lake appeared to be the recipient of the transient seals to a much greater extent than the ice near Aialik Glacier (Fig. 4). 

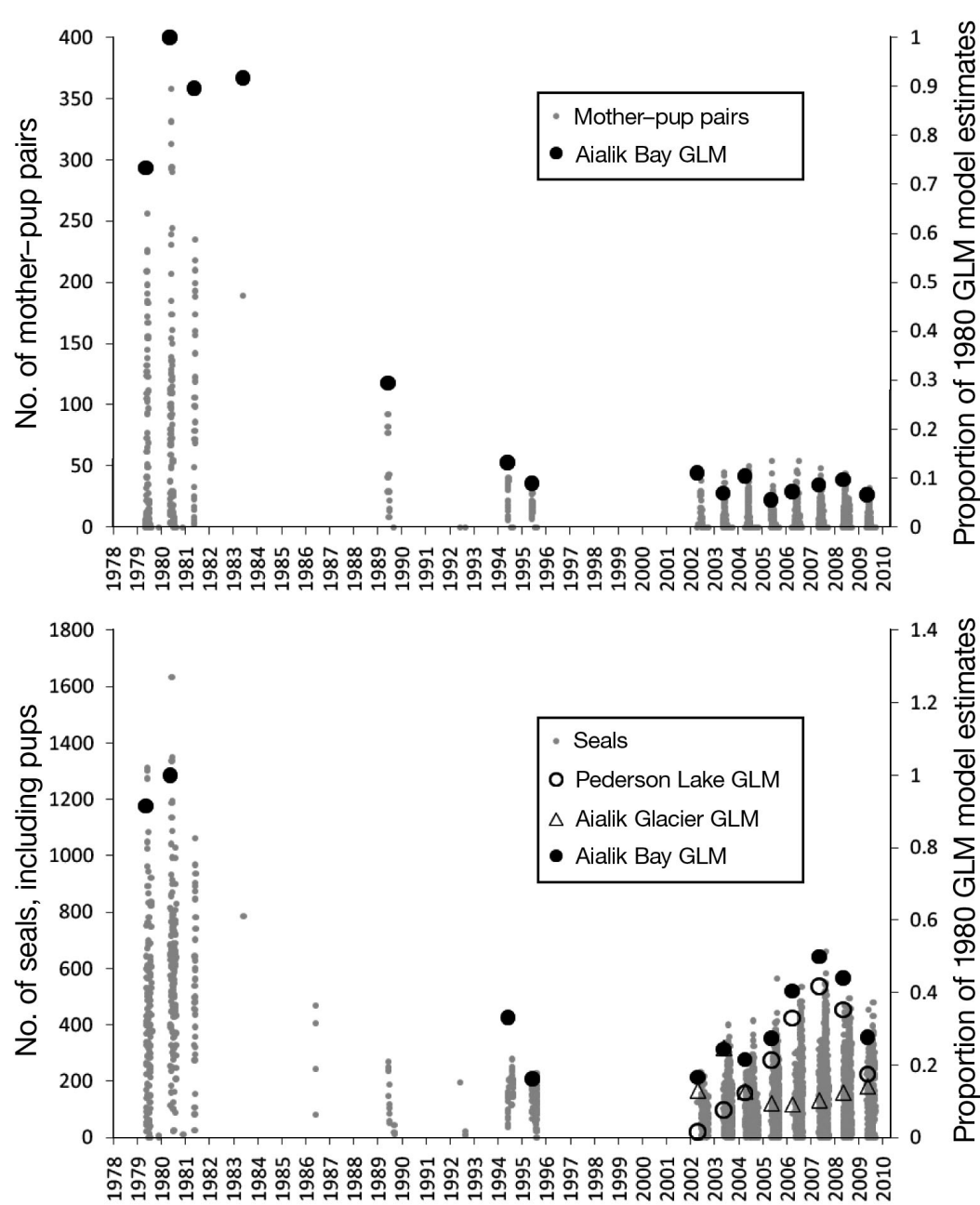

Fig. 4. Phoca vitulina richardsi. Numbers of seals counted (grey dots) and the proportional variation in general linear model (GLM) count estimates, relative to 1980, adjusted for favorable standardized haulout conditions. The top panel refers to mother-pup pairs while the bottom panel represents the number of seals present during the molt. Solid black circles indicate GLM estimates for Aialik Bay (Aialik and Pedersen glacier sites combined), open symbols signify the proportional changes of GLM estimates for Pedersen Lake (circles) and Aialik glacier (triangles) relative to 1980

\section{DISCUSSION}

\section{Population trends}

Pup counts in Aialik Bay indicate a dramatic reduction in reproduction of harbor seals during the past $30 \mathrm{yr}$ that is failing to improve. In the early 1980s, roughly 250 pups were born each year on ice near Aialik Glacier. Since 1983, the number of pups precipitously declined by $12.4 \%$ annually to fewer than 40 pups by 1994. Since 1994, the number of pups continued to decline by $4.6 \% \mathrm{yr}^{-1}$ through 2009 . The timing of the decline coincides with the decline of similar magnitude at Tugidak Island, a terrestrial site and the only other location in the Gulf of Alaska where long- term pup counts were determined, and where the number of pups diminished from more than 2000 in 1976 to about 200 by 1994 (Pitcher 1990, Jemison \& Kelly 2001). However, in contrast to the continuing decline of pups in Aialik Bay, the number of pups at Tugidak Island have been increasing by $5.4 \%$ $\mathrm{yr}^{-1}$ since 1994 (Jemison \& Kelly 2001, Jemison et al. 2006).

Survey methods changed from field counts to camera counts during the course of this study, which potentially could have introduced bias when population trends were estimated. Comparisons of counts of seals obtained from cameras at Squab Island, where field counts were made in 1979 to 1998, and Aialik Glacier were used to evaluate this possibility. Differences in numbers of seals counted across the $2 \mathrm{~km}$ span between Squab Island and Aialik Glacier were compared (ASLC unpubl. data). Results varied depending on the distribution of seals, but overall, the number of seals and pups detected from each camera were similar and repeated counts conducted during the day provided further reassessments as seals drifted past Squab Island. Even so, distinguishing seals from dirty ice and distinguishing pups near the glacier was easier when the higher altitude Aialik Glacier camera was used. The better viewing provided by the Aialik Glacier camera might thus have increased counts, and introduced an upward bias relative to the 1979 to 1998 field counts. This bias would have reduced differences between field and camera counts, and led to an underestimate of the extent of the decline. The steepest phase of the decline in Aialik Bay was documented using comparable field counts conducted from 1979 to 1995. Camera counts, begun in 2002, have documented the population dynamics of seals following the precipitous phase of the decline. The rapid rate of decline documented in Aialik Bay coincided with declining numbers of harbor seals on Tugidak Island and Prince William Sound (Frost et al. 1999, Jemison et al. 2006, G. Pendleton unpubl. data) indicating influences from broader scale ecological effects.

Population trends of molting seals were more difficult to interpret for Aialik Bay owing to expanding habitat near Pedersen Glacier and apparently high 
Table 3. Phoca vitulina richardsi. Generalized linear model (GLM) mean and adjusted count estimates of harbor seals near Aialik Glacier and annual mean Total Count estimates of seals, including those at Pedersen Lake, from 1979 to 2009. $\mathrm{N}$ is the number of surveys. Numbers in parentheses represent $95 \%$ CI. Superscripts identify the annual percent rate of change for specified time periods indicated in footnotes (negative percent indicates decline)

\begin{tabular}{|c|c|c|c|c|}
\hline Level & $\mathrm{N}$ & $\begin{array}{l}\text { Aialik } \\
\text { mean }\end{array}$ & $\begin{array}{c}\text { Aialik } \\
\text { adjusted }\end{array}$ & $\begin{array}{c}\text { Total Counts } \\
\text { mean }\end{array}$ \\
\hline 1979 & 27 & $\begin{array}{c}547^{\mathrm{a}, \mathrm{d}} \\
(535-560)\end{array}$ & $\begin{array}{c}913.6^{\mathrm{e}, \mathrm{h}} \\
(1107-754)\end{array}$ & $\begin{array}{c}547^{\mathrm{i}, 1} \\
(528-567)\end{array}$ \\
\hline 1980 & 30 & $\begin{array}{c}598^{\mathrm{a}, \mathrm{d}} \\
(586-609)\end{array}$ & $\begin{array}{c}967.72^{\mathrm{e}, \mathrm{h}} \\
(1158-808)\end{array}$ & $\begin{array}{c}598^{\mathrm{i}, \mathrm{l}} \\
(570-616)\end{array}$ \\
\hline 1994 & 22 & $\begin{array}{c}198^{\mathrm{a}, \mathrm{d}} \\
(184-212)\end{array}$ & $\begin{array}{c}312.9^{\mathrm{e}, \mathrm{h}} \\
(404-242)\end{array}$ & $\begin{array}{c}198^{\mathrm{i}, 1} \\
(176-220)\end{array}$ \\
\hline 1995 & 64 & $\begin{array}{c}97^{\mathrm{b}, \mathrm{d}} \\
(89-105)\end{array}$ & $\begin{array}{c}146.6^{\mathrm{f}, \mathrm{h}} \\
(184-117)\end{array}$ & $\begin{array}{c}97^{\mathrm{j}, 1} \\
(84-110)\end{array}$ \\
\hline 1996 & 37 & $\begin{array}{c}136^{\mathrm{b}, \mathrm{d}} \\
(126-147)\end{array}$ & $\begin{array}{c}194^{\mathrm{f}, \mathrm{h}} \\
(155-242)\end{array}$ & $\begin{array}{c}136^{\mathrm{j}, 1} \\
(120-153)\end{array}$ \\
\hline 1997 & 7 & $\begin{array}{c}267^{\mathrm{b}, \mathrm{d}} \\
(243-292)\end{array}$ & $\begin{array}{c}438.9^{\mathrm{f}, \mathrm{h}} \\
(301-641)\end{array}$ & $\begin{array}{c}267^{\mathrm{j}, 1} \\
(229-306)\end{array}$ \\
\hline 2002 & 32 & $\begin{array}{c}71^{\mathrm{b}, \mathrm{d}} \\
(60-83)\end{array}$ & $\begin{array}{c}126.8^{\mathrm{f}, \mathrm{h}} \\
(173-93)\end{array}$ & $\begin{array}{c}100^{\mathrm{j}, 1} \\
(82-118)\end{array}$ \\
\hline 2003 & 125 & $\begin{array}{c}94^{\mathrm{c}, \mathrm{d}} \\
(89-100)\end{array}$ & $\begin{array}{c}187.4^{\mathrm{g}, \mathrm{h}} \\
(154-228)\end{array}$ & $\begin{array}{c}146^{\mathrm{k}, \mathrm{l}} \\
(136-155)\end{array}$ \\
\hline 2004 & 154 & $\begin{array}{c}51^{\mathrm{c}, \mathrm{d}} \\
(46-57)\end{array}$ & $\begin{array}{c}102.1^{\mathrm{g}, \mathrm{h}} \\
(126-83)\end{array}$ & $\begin{array}{c}129^{\mathrm{k}, \mathrm{l}} \\
(121-137)\end{array}$ \\
\hline 2005 & 231 & $\begin{array}{c}29^{\mathrm{c}, \mathrm{d}} \\
(25-34)\end{array}$ & $\begin{array}{c}62.8^{g, h} \\
(79-50)\end{array}$ & $\begin{array}{c}164^{\mathrm{k}, \mathrm{l}} \\
(157-170)\end{array}$ \\
\hline 2006 & 161 & $\begin{array}{c}34^{\mathrm{c}, \mathrm{d}} \\
(29-39)\end{array}$ & $\begin{array}{c}68.4^{\mathrm{g}, \mathrm{h}} \\
(87-54)\end{array}$ & $\begin{array}{c}242^{\mathrm{k}, \mathrm{l}} \\
(234-250)\end{array}$ \\
\hline 2007 & 171 & $\begin{array}{c}26^{\mathrm{c}, \mathrm{d}} \\
(21-31)\end{array}$ & $\begin{array}{c}65^{\mathrm{g}, \mathrm{h}} \\
(84-50)\end{array}$ & $\begin{array}{c}299^{\mathrm{k}, 1} \\
(292-307)\end{array}$ \\
\hline 2008 & 189 & $\begin{array}{c}49^{\mathrm{c}, \mathrm{d}} \\
(44-53)\end{array}$ & $\begin{array}{c}94^{\mathrm{g}, \mathrm{h}} \\
(116-77)\end{array}$ & $\begin{array}{c}264^{\mathrm{k}, 1} \\
(256-271)\end{array}$ \\
\hline 2009 & 101 & $\begin{array}{c}53^{\mathrm{c}, \mathrm{d}} \\
(47-60)\end{array}$ & $\begin{array}{c}103^{g, h} \\
(130-82)\end{array}$ & $\begin{array}{c}166^{\mathrm{k}, \mathrm{l}} \\
(155-176)\end{array}$ \\
\hline
\end{tabular}

Geometric mean of mean Aialik Glacier annual rate of change:

a $-6.5 \%(1979-1994),{ }^{b}-6.0 \%(1995-2002)$,

c-4.1\% (2003-2009), d $-5.8 \%(1979-2009)$

Geometric mean of adjusted Aialik Glacier annual rate of change:

e-6.9\% (1979-1994), f $-10.7 \%(1995-2002)$,

g-2.9\% (2003-2009), ${ }^{\mathrm{h}}-7.0 \%(1979-2009)$

Geometric mean of mean Total Counts annual rate of change:

${ }^{\mathrm{i}}-6.5 \% \mathrm{yr}^{-1}(1979-1994),{ }^{\mathrm{j}}-8.2 \% \mathrm{yr}^{-1}(1995-2002)$,

${ }^{\mathrm{k}} 7.5 \% \mathrm{yr}^{-1}$ (2003-2009), ${ }^{1}-3.9 \% \mathrm{yr}^{-1}$ (2003-2009)

variability in site selection by molting seals. Hoover (1983) detected disproportionately low numbers of adult seals relative to subadults that used ice near Aialik Glacier during the molt in 1979 and 1980. Similarly, our surveys indicated peak numbers near Aialik Glac- ier during late July, when young subadult seals molt (Daniel et al. 2003), and lower numbers later in the season, when adults molt. Hoover (1983) indicated that older seals may have molted at other locations because of ice limitations. With far fewer seals present in recent years, ice has not been a limiting factor.

Habitat in Pedersen Lake exposed by the retreat of Pederson Glacier has been used by seals since the early 1990s. Although a few pups have been born there and older pups visit the lake, Pedersen Lake primarily has been used by seals without pups, particularly in early spring and during the molt. Although seals undoubtedly move between Aialik and Pedersen glaciers, seals seasonally appear to associate with one location. Except in spring, immediately before pupping, we saw little indication of seals shifting haulout locations from Pedersen Lake to near Aialik Glacier en mass. During windy weather, when ice was blown away from Aialik Glacier and seals were unable to haul out, we did observe increased numbers near Pedersen Glacier.

Interpreting counts from Pedersen Lake is challenging since we do not know the proportions of seals that primarily associate with Aialik Bay or that come from other locations, such as Northwestern Fjord, a tidewater glacial fjord $60 \mathrm{~km}$ to the west by water. Nevertheless, the magnitude of change we observed indicates that during the molt, seals demonstrated considerable flexibility in choice of haulout location.

Harbor seal population monitoring in Alaska primarily relies on counts obtained during the molt via regional aerial surveys (e.g. Boveng et al. 2003, Small et al. 2003). Regional surveys mitigate influences of seal movements between haulouts, providing source and destination haulouts are included in the survey route (Hoover-Miller et al. 2001). Our observations indicate that molting seals that use glacial ice in Aialik Bay adjust their distribution in response to environmental conditions. We observed a transient influx of seals into upper Aialik Bay from 2005 to 2009, which corresponded to colder than normal water temperatures and enhanced stratification in the northern Gulf of Alaska (Arimitsu 2009, Janout et al. 2010). Increasing numbers of total seals counted in August from 2002 to 2007 also suggested that environmental conditions associated with the expanding habitat in Pedersen Lake may have been favorable for molting seals. After 2007, congested ice conditions or warming marine conditions reduced the number of seals present and/or shortened the amount of time they hauled out. For developing regional population trends, a larger geographic range needs to be measured; however, further investigation of attributes associated with local influxes can provide insight into factors associated with particular tidewater glacial fjords that provide important habitats for seals. 
The results of the present study reinforce the need for consistency in the timing of surveys conducted during the molt. Timing of molt assessments resulted in different trend trajectories (Fig. 3). In Aialik Bay, trends in Total Counts of primarily molting juveniles observed early in the season differed from trends in numbers of molting older seals counted later in the season. From 1979 to 1980, molting patterns of subadults and adults in Aialik Bay showed similar molt phenology as observed on Tugidak Island, with subadults tending to molt before adults (Hoover 1983). Numbers of adults counted in upper Aialik Bay declined after the pupping period, but were not observed to increase during the first half of August as would be predicted by Daniel et al. (2003). Although observations by Hoover (1983) in 1980 did not extend into the peak period when adult males molted on Tugidak Island, age composition was assessed through August 20 and should have detected an increase in numbers of molting adult females and increasing numbers of adult males in premolt condition, indicating that older seals molted elsewhere. Hoover (1983) concluded that low numbers of seals observed during the molt may have been the result of poor ice conditions during August relative to the number of seals needing to haul out. Whether the differences we observed in haulout attendance represent behavioral avoidance between age groups, or environmental conditions that favored or inhibited specific age classes, cannot be confirmed and needs further investigation.

\section{Pupping phenology}

Regional differences in the timing of pupping have been associated with latitude in some locations, but are also influenced by geographic variation in selective factors that are potentially smoothed by genetic exchange (Temte et al. 1991). Nutritional stress has been associated with a delay in embryonic development for harbor seals (Bowen et al. 2003), grey seals Halichoerus grypus (Boyd 1984), Antarctic fur seals Arctocephalus gazella (Lunn \& Boyd 1993, Boyd 1996) and South American sea lions Otaria flavescens (Soto et al. 2004). At Sable Island off Nova Scotia, Canada, known individual harbor seals were studied over periods of population increases and decreases associated with shark predation and nutritional stress (Bowen et al. 2003). Mean parturition dates averaged $6 \mathrm{~d}$ earlier during the period of relatively stable pup production than during the period of decline. Bowen et al. (2003) documented that maternal age also was positively correlated with parturition date, with older females giving birth later than younger seals. Even so, a longitudinal comparison of known-age females indicated a 4 d delay in parturition during the period of declining pup production compared with the period of stable production after effects of age were accounted for. Jemison \& Kelly (2001) and Jemison et al. (2006) also described marked differences in haulout, demographics and parturition dates during periods of decline and initial recovery at Tugidak Island, including a 2 to $4 \mathrm{wk}$ shift in dates of peak counts during pupping and molting periods. During the 1970 s the onset and peak of pupping occurred 6 to $18 \mathrm{~d}$ later than during the 1990s. Jemison \& Kelly (2001) related differences in pupping phenology and demography with environmental changes that potentially altered haulout characteristics associated with body condition and foraging time at sea. Observations at Tugidak Island and Sable Island suggest that changes in pupping phenology occur with population decline, with earlier parturition associated with better condition of seals and stable or increasing trajectories. In Aialik Bay, we observed shifts to earlier parturition dates between the 1980s and 2003 to 2009 . Although the rate of decline slowed, numbers of pups born in Aialik Bay have failed to increase despite earlier parturition, indicating that conditions continue to remain unfavorable for successful reproduction and weaning of pups.

The persistent decline of harbor seals in Aialik Bay, particularly pups, contrasts with trends at non-glacial sites in the Gulf of Alaska and southeast Alaska, where populations have been stable or increasing since the mid-1990s (Small et al. 2003, Jemison et al. 2006, G. Pendleton unpubl. data). The persistent population decline in Glacier Bay (Mathews \& Pendleton 2006, Womble et al. 2010), which also contrasts with trends in surrounding areas (Small et al. 2003), raises concern over the integrity of glacial fjord ecosystems and the future of harbor seals reliant on glacial habitats in Alaska. In the present study, we observed a temporary influx of seals into Pedersen Lagoon that was more extensive than a simple movement from Aialik Glacier. We suspect many of those seals travelled to Aialik Bay from Northwestern Fjord. On the other hand, continued diminishing numbers of harbor seals, particularly pups, near Aialik Glacier, suggest reduced recruitment of reproductive females in Aialik Bay or movements of reproductive females from Aialik Bay. Such changes may result from temporal and spatial differences in ecological attributes influencing foraging opportunities (Arimitsu 2009), effects of northwest winds on ice availability during pupping (Hoover 1983) or growth in tourism and the likelihood of disturbance (Jezierski 2009). Seals using glacial ice substrates appear flexible in their behavior and response to environmental change, but additional research, particularly telemetry 
studies to assess foraging locations and movements of seals, are needed to help distinguish which environmental attributes are associated with the diminishing use of once important glacial habitats.

Acknowledgements. We thank the numerous organizations who have supported harbor seal monitoring in Aialik Bay during the past $30 \mathrm{yr}$, including the US National Park Service, Port Graham Corporation, National Maritime Wildlife Refuge System, 'Exxon Valdez' Oil Spill Trustee Council. We particularly thank E. C. Murphy, A. Castellina and the late F. H. Fay, who were instrumental in establishing long-term monitoring in Aialik Bay. We also thank the numerous people who aided with field surveys including R. Day, K. Oakley, T. Carpenter, D. Miller, C. Miller, M. Tetreau, J. Pfeiffenberger, S. Pfeiffenberger, G. Smith, K. Link, W. Bryden, J. Welsh, S. Brennan, P. Salzman, K. Wilson and the following people who spent endless hours operating the remote video cameras and reviewing tapes: K. Felitz, S. Aughe, L. O'Brien, L. Dickinson, J. Follin, T. Mauro, M. Sternberg, K. Heffron, R. Pearce, A. Graefe, K. Stade, K. Williams, L. Cramer, G. Mills, K. Marino, S. Slaughter, T. Zaffarano, C. Youngflesh, N. Beckmann, S. Hishmeh, J. Mahoney, A. Bishop, L. Marcella, M. Caulfield, J. Albers, M. Terwilliger and C. Jezierski. Research and data synthesis was supported by the National Park Service, Ocean Alaska Science and Learning Center, 'Exxon Valdez' Oil Spill Trustee Council and the National Marine Fisheries Service (NMFS). We are especially grateful for valuable comments and suggestions provided by G. Pendleton, A. Springer and 3 anonymous reviewers on earlier drafts of the manuscript. This study was carried out under NMFS General Authorization for Scientific Research Letter of Confirmation No. 881-1673 and 881-1918, National Park Service Scientific Research Permit KEFJ-2004-SCI-0001 and KEFJ-2008-SCI-0001, Port Graham Corporation MOU, US Fish and Wildlife Service Special Use Permit 74500-03-045 and 10-001, Department of Natural Resources Permit 09-KA-698.

\section{LITERATURE CITED}

Adkison MD, Quinn TJ, Small RJ (2003) Evaluation of the Alaska harbor seal (Phoca vitulina) population survey: a simulation study. Mar Mamm Sci 19:764-790

Arimitsu ML (2009) Environmental gradients and prey availability relative to glacial features in Kittlitz's Murrelet foraging habitat. MS thesis, University of Alaska Fairbanks

Bengtson JA, Phillips AV, Mathews A, Simpkins MA (2007) Comparison of survey methods for estimating abundance of harbor seals (Phoca vitulina) in glacial fjords. Fish Bull 105:348-355

Bishop RH (1967) Reproduction, age determination and behavior of the harbor seal, Phoca vitulina L. in the Gulf of Alaska. MS thesis, University of Alaska Fairbanks

Boveng PL, Bengtson JL, Withrow DE, Cesarone JC, Simpkins MA, Frost KJ, Burns JJ (2003) The Abundance of harbor seals in the Gulf of Alaska. Mar Mamm Sci 19:111-127

Bowen WD, Ellis SL, Iverson SJ, Boness DJ (2003) Maternal and newborn life-history traits during periods of contrasting population trends: implications for explaining the decline of harbour seals, Phoca vitulina, on Sable Island. J Zool 261:155-163

Boyd IL (1984) The relationship between body condition and the timing of implantation in pregnant Grey seals (Halichoerus grypus). J Zool 203:113-123
Boyd IL (1996) Individual variation in duration of pregnancy and birth date in Antarctic fur seals: the role of environment, age and sex of fetus. J Mammal 77:124-133

Calambokidis J, Taylor BL, Carter SD, Steiger GH, Dawson PK, Antrim LD (1987) Distribution and haulout behavior of harbor seals in Glacier Bay, Alaska. Can J Zool 65: 1391-1396

Calcagno V (2009) glmulti: GLM model selection and multimodel inference made easy. $\mathrm{R}$ package $\mathrm{v}$. 0.6-2. http//:CRAN.R-project.org/package=glmulti

> Daniel R, Jemison LA, Pendleton GW, Crowley SM (2003) Molting phenology of harbor seals on Tugidak Island, Alaska. Mar Mamm Sci 19:128-140

Frost KJ, Lowry LF, Sinclair E, Ver Hoef J, McAllister D (1994) Impacts on distribution, abundance, and productivity of harbor seals. In: Loughlin TR (ed) Marine mammals and the Exxon Valdez. Academic Press, San Diego, CA, p 97-118

> Frost KJ, Lowry LF, Sinclair E, Ver Hoef JM (1999) Monitoring the trend of harbor seals in Prince William Sound, Alaska, after the Exxon Valdez oil spill. Mar Mamm Sci 15:494-506

Grant US, Higgins DF (1913) Glaciers of Prince William Sound and Kenai Peninsula. US Geol Surv Bull 526

> Hare SR, Mantua NJ (2000) Empirical evidence for North Pacific regime shifts in 1977 and 1989. Prog Oceanogr 47: 103-145

Hoover AA (1983) Behavior and ecology of harbor seals (Phoca vitulina richardsi) inhabiting glacial ice in Aialik Bay, Alaska. MS thesis, University of Alaska Fairbanks

Hoover-Miller AA (1994) Harbor seals (Phoca vitulina): biology and management $\mathrm{n}$ Alaska. Report to the Marine Mammal Commission. Washington, DC

> Hoover-Miller AA, Parker KR, Burns JJ (2001) A reassessment of the impact of the Exxon Valdez oil spill on harbor seals (Phoca vitulina) in Prince William Sound. Mar Mamm Sci 17:111-135

> Janout MA, Weingartner TJ, Royer TC, Danielson SL (2010) On the nature of winter cooling and the recent temperature shift on the northern Gulf of Alaska shelf. J Geophys Res 115:C05023 doi:10.1029/2009JC005774

> Jemison LA, Kelly BP (2001) Pupping phenology and demography of harbor seals on Tugidak Island, Alaska. Mar Mamm Sci 17:585-600

Jemison LA, Pendelton GW, Wilson CA, Small RJ (2006) Long-term trends in harbor seal numbers at Tugidak Island and Nanvak Bay, Alaska. Mar Mamm Sci 22: $339-360$

Jezierski C (2009) The impact of sea kayak tourism and recreation on harbor seal behavior in Kenai Fjords National Park: integrating research with outreach, education, and tourism. MS thesis, University of Alaska Fairbanks

Link WA, Sauer JR (1997) Estimation of population trajectories from count data. Biometrics 53:488-497

Lunn NJ, Boyd IL (1993) Effects of maternal age and condition on parturition and the perinatal period of Antarctic fur seals. J Zool 229:55-67

> Mathews EA, Kelly BP (1996) Extreme temporal variation in harbor seals (Phoca vitulina richardii) numbers in Glacier Bay, a glacial fjord in southeast Alaska. Mar Mamm Sci 12: 483-488

Mathews EA, Pendleton GW (2006) Declining trends in harbor seals (Phoca vitulina) numbers in Glacier Bay National Park, 1992-2002. Mar Mamm Sci 22:167-189

Mazerolle MJ (2009). AICcmodavg: model selection and multimodel inference based on (Q)AIC(c). R package v. 1.06. http://medipe.psu.ac.th/cran-r/web/packages/ AICcmodavg/

Molnia BF (2008) Glaciers of North America. In: Williams RS 
Jr, Ferrigno JG (eds) Glaciers of Alaska. Satellite image atlas of glaciers of the world. US Geol Surv Bull Prof Pap 1386-K

Pitcher KW (1990) Major decline in number of harbor seals, Phoca vitulina richardsi, on Tugidak Island, Gulf of Alaska. Mar Mamm Sci 6:121-134

Post A (1980) Preliminary bathymetry of Aialik Bay and neoglacial changes of Aialik and Pederson Glaciers. US Geol Surv Bull Open-File Rep 80-423

R Development Core Team (2010) The R Project for statistical computing. www.r-project.org

SAS Institute 2009. JMP ${ }^{\circledR} 8$ statistics and graphics guide, 2nd edn. SAS Institute, Cary, NC

Savarese DM (2004) Seasonal trends in harbor seal (Phoca vitulina richardsii) abundance at the Bering Glacier in south central Alaska. MS thesis, University of Alaska Anchorage

Small RJ, Pendleton GW, Pitcher KW (2003) Trends in abundance of Alaska harbor seals, 1983-2001. Mar Mamm Sci 19:344-362

Small RS, Boveng PL, Byrd GV, Withrow DE (2008) Harbor seal population decline in the Aleutian Archipelago. Mar Mamm Sci 24:845-863

Soto KH, Trites AW, Arias-Schreiber M (2004) The effects of

Editorial responsibility: Hans Heinrich Janssen, Oldendorf/Luhe, Germany prey availability on pup mortality and the timing of birth of South American sea lions (Otaria flavescens) in Peru. J Zool 264:419-428

> Temte JL, Bigg MA, Wiig O (1991) Clines revisited: the timing of pupping in the harbour seal (Phoca vitulina). J Zool 224: 617-632

Thompson P, Rothery P (1987) Age and sex differences in the timing of moult in the common seal, Phoca vitulina. J Zool 212:597-603

Trillmich F, Mohren W (1981) Effects of the lunar cycle on the Galapagos fur seal, Arctocephalus galapagoenusis. Oecologia 48:85-92

> Ver Hoef JM, Frost KJ (2003) A Bayesian hierachical model for monitoring harbor seal changes in Prince William Sound, Alaska. Environ Ecol Stat 10:201-219

> Watts P (1993) Possible lunar influence on hauling-out behavior by the Pacific harbor seal (Phoca vitulina richardsi). Mar Mamm Sci 9:68-76

Womble JN, Pendleton GW, Mathews EA, Blundell GM, Bool NM, Gende SM (2010) Harbor seal (Phoca vitulina richardii) decline continues in the rapidly changing landscape of Glacier Bay National Park, Alaska, 1992-2008. Mar Mamm Sci 26:686-697

Submitted: July 9, 2010; Accepted: December 12, 2010

Proofs received from author(s): February 13, 2011 